\title{
Integrating services, collaborating, and developing connections with schools
}

\section{Lawson, Hal A;Sailor, Wayne}

Focus on Exceptional Children; Oct 2000; 33, 2; Research Library

pg. 1

VOLUME 33

NUMBER 2

OCTOBER 2000

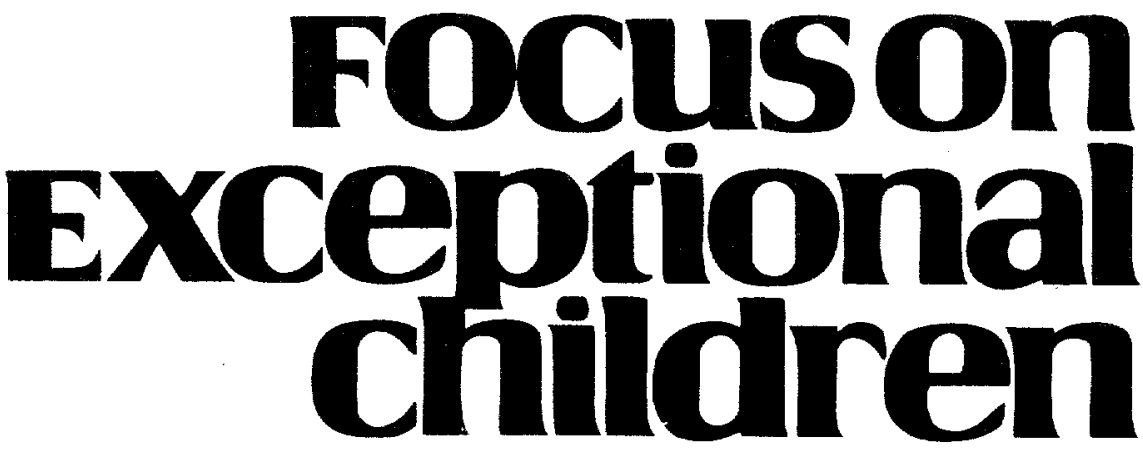

\section{Integrating Services, Collaborating, and Developing Connections with Schools}

Hal A. Lawson and Wayne Sailor

When a new cottage industry develops around a bewildering array of buzzwords, something important is happening. When competent people from all walks of life struggle to make sense of these buzzwords, they are identifying important policy needs and problems with practice. When schools are in trouble, and when results for vulnerable children, youth, and families do not improve, the seeds are being sown for self-doubt, cynicism, skepticism, and maltreatment dynamics. When practicing professionals protect themselves from blame by pointing their fingers at others, when they manifest some of the same needs as the most vulnerable families, and when a growing number of them burn out and drop out, systemic problems are being implicated.

When children kill other children, their teachers, and their parents, and when America's schools become their killing fields, something is clearly wrong, and that something needs to be fixed. When no one knows all that's wrong, and when there are competing definitions of what is wrong that needs fixing and what is good and right that needs strengthening, individuals, groups, entire professions, and organizations often work at cross-purposes. As they work at cross-purposes, they are effectively manufacturing diversity and simultaneously adding to the list of buzzwords. Finally, when the American "quick-fix mentality" reigns, even the most promising innovations often are constrained, stalled, or eliminated because of insufficient time, limited resources, inadequate supports, and ill conceived evaluations.

The state of the art and science of integrated services - the topic addressed herebelongs in this context. For example, the concept of integrated services has become a mainstay in the buzzword industry. In fact, integrated services is associated with a long list of companion buzzwords. These include: interprofessional collaboration, interdisciplinary case management, inter-agency coordination; interprofessional education and training, capitated services community schools, full-service schools, charter schools, voucher and choice plans, asset-based youth development, policy decategorization, systems change and cross-systems change, and comprehensive systems of care. The length of this list is sufficiently bewildering. It becomes all the more challenging when human beings use these buzzwords. Often, they have in mind different meanings when they use the same words, and they mean the same things when they use different buzzwords (Lawson \& Briar-Lawson, 1997).

Hal Lawson is affiliated with the University at Albany, State University of New York. Wayne Sailor is with the University of Kansas.

C Love Publishing Company, 2000 
Challenges like these are not limited to the United States. Like other American industries, this buzzword industry, including integrated services, has a global reach (e.g., OECD, 1998; van Veen, Day, \& Waldren, 1998). International comparisons and examples add to the diversity and complexity. Obviously, the topic of integrated services demands an entire book, and our analysis is unavoidably selective and limited.

Thus, we approach the topic of integrated services with considerable humility and with a clear sense of purpose. Our aim is to provide an action-oriented planning framework. Toward this aim, we have identified four related goals:

1. To foster shared meaning and understanding

2. To promote improved policies and practices;

3. To enable self-directed learning

4. To contribute to improvements in the well-being of children, youth, and families and in the working lives of the professionals who serve them.

Like all action-oriented frameworks, ours is grounded in firm value commitments, implicit in our sensitizing language as well as in the critical and evaluative narrative we provide. Predictably, our value commitments are most evident when we shift from a descriptive-evaluative narrative to a normative-prescriptive one.

\section{Focuson
Exceptional
childiren}

ISSN $0015-511 \mathrm{X}$

FOCUS ON EXCEPTIONAL CHILDREN (USPS 203-360) is published monthly except June. July, and August as a service to teachers, special educators. curriculum specialists, administrators, and those concerned with the special education of exceptional children. This publication is annotated and indexed by the ERIC Clearinghouse on Handicapped and Gifted children for publication in the monthly Current Index to Joumals in Education (CLE) and the quarterly index, Exceptional Children Education Resources (ECER). The full text of Focus on Exceptional Children is also available in the electronic versions of the Education Index. It is also available in microfilm from Xerox University Microfilms, Ann Arbor, MI. Subscription rates: Individual, \$30 per year; institutions, $\$ 40$ per year. Copyright $(0) 2000$. Love Publishing Company. All rights reserved. Reproduction in whole or part without written permission is prohibited. Printed in the United States of America. Periodicals postage is paid at Denver, Colorado. POSTMASTER: Send address changes to:

$$
\begin{gathered}
\text { Love Publishing Company } \\
\text { Executive and Editorial Office } \\
\text { P.O. Box } 22353 \\
\text { Denver. Colorado } 80222 \\
\text { Telephone (303) } 221-7333
\end{gathered}
$$

$\begin{array}{cc}\begin{array}{c}\text { Karen Harris } \\ \text { University of Maryland }\end{array} & \begin{array}{c}\text { Thomas Skrtic } \\ \text { University of Kansas }\end{array} \\ \text { James Shriner } & \text { Stanley F. Love } \\ \text { University of Illinois } & \text { Publisher }\end{array}$

As our title suggests, we emphasize three related, but analytically different, processes; integrating services, collaborating, and developing connections with schools. We are convinced that such a process emphasis lends precision to planning, implementation, evaluation, and research; and that precision is needed today. On the other hand, our process emphasis is not an end in itself. We argue that these three processes are becoming best-practice strategies because they promise to improve results. With Gardner (1999), we promote results-oriented accountability, along with learning and improvements systems in support of progress charting, theory development, and barrier busting. Improved results are the aim, then, and integrating services, collaborating, and developing connections with schools are three related processes for achieving this aim.

Some of the most basic, practical questions in life also are the most important ones. What are integrated services? Why are they being developed and promoted? Who is promoting them? Where? How are they being implemented and evaluated? Whose needs and interests do they serve? What difference do they make? Do they improve children's learning and school performance? What are some of the main barriers, lessons learned, and facilitators? Are there areas of selectivity and silence? Is today's approach as good as it gets? If not, what is next? These kinds of questions structure our analysis of integrated services and its companion concepts.

We begin by sketching a context for integrated services. Once we have provided aspects of its history, we focus on the modern service integration initiatives. We suggest that they can be viewed as forming five different (but not mutually exclusive) waves, and that each carries its own meanings, definitions, and functions. After we have identified some of the conflicts and alternatives, we offer our working definition of integrated services and its close companion concept, interprofessional collaboration. Then we connect our analysis to schools. Next we describe the complexity, difficulties, and opportunities associated with school-related integration and collaboration. Here, we rely on three of the five waves to emphasize important choices and developmental processes. We conclude by exploring emergent challenges for American democracy.

\section{SKETCHING A CONTEXT}

Our analysis begins with the historical context. Upon closer inspection, service integration has an interesting history (e.g., Halpern, 1999b; Hassett \& Austin, 1997; O'Looney, 1996; Tyack, 1992). Although schools have been mentioned in some cases, and they are implicated in others, the fact remains that service integration can be viewed as a unique initiative involving immensely complex changes. 
Viewed in this historical context, modern service integration initiatives aim to reform and transform the institutionbuilding efforts of the late 19th century and most of the 20th century. Industrial-age thinking and planning, which relied on the root metaphor of the machine and the assembly line, served as the crucible for an array of specialized helping professions. Reflecting and fueling their efforts, organizations such as schools and social service agencies were instituted to house these professions. Specialized, categorical governmental policy sectors (e.g.. education, social welfare) developed in support of these professions and their organizations.

Each profession and its respective organizations claimed that it met a specific human need, or that it addressed a significant social problem. The underlying assumption was (and is) that each need or problem could be isolated and categorized. Once isolated and categorized, it could be assigned to the relevant profession. Each profession (e.g. educators) and its organization (e.g., schools) assumed responsibility for solving special problems and meeting special needs (e.g., children's learning and healthy development). In turn, these professions' and organizations' external accountability systems developed in relation to their selfproclaimed responsibilities. An entire system of professions has evolved in the process (e.g., McKnight, 1995).

Risking exaggeration, for nearly every conceivable part of the human being, there is now a specialized profession (Lawson, 1998). Unfortunately, the professions have competed with each other. This competition is inevitable because the current system has an economic dimension; it is market-driven (Abbott, 1988; Lawson, 2001; McKnight, 1995). Each profession seeks the equivalent of an economic monopoly over practice areas and special categories of people. Simultaneously, it seeks cultural power and authority. As it gains power and authority, it strengthens its abilities to influence policy decisions in support of its respective professional monopoly. This system of discrete, self-contained professions sets the stage for the contemporary service integration movement.

\section{Today's Service Integration Movement}

Today's service integration movement began in the early 1970 's (Gerry, in press). At that time, the federal government had a separate department of health, education, and welfare. Its secretary, Elliott Richardson, publicized the problems associated with so many categorical funding and program initiatives. Allegedly, he summed up his "diagnosis" of the federal bureaucracy's "disease" by claiming that it suffered from "a hardening of the categories." 'The cures included de-categorizing and blending funding, while integrating programs and services.

\footnotetext{
${ }^{1}$ For example, Gerry (in press) claims that the 1998 Federal Budget included more than 500 separate, categorically identified programs, and at least 300 of them were intended for children and families.
}

Because the system of professions is reinforced by these hardened categories, it was implicated as part of the problem. It was (and is) characterized as uncoordinated, fragmented, duplicative, and inefficient (e.g., Gardner, 1999; Lawson, 1998). For example, children and families manifesting multiple needs and problems have as many as 14 different professionals in their lives (Briar-Lawson \& Drews, 1998; Halpern, 1999b). These professionals often are unaware of each other. They also have different conceptions of needs and problems, and they rely on different language systems and interventions. Consequently, they often work at cross-purposes.

Predictably, children and families are not served effectively, and results often do not improve. Even worse, competing service providers may cause harm. They may force-fit their preferred diagnostic categories and intervention strategies on families instead of tailoring their assessments and interventions. Or their problem-focused, deficit-oriented language may shape the self-definitions of children and families, resulting in learned hopelessness, depression, and despair.

In this line of thinking, the system of professions and its correlates are the problem (disease). If so, service integration and its companions (e.g., collaboration) are the solution (cure).

\section{Five Waves of Service Integration}

Waldfogel (1997) analyzed federal and state policies, incentives, and innovations related to service integration. She described "two waves" of service integration.

\section{First Wave}

Waldfogel's first wave was formed during the 1970s and the early 1980s by top-down mandates for integration. This wave continues today. For example, the state of Minnesota, like the Canadian Province of British Columbia, has integrated once separate governmental departments (ministries) into one. Other states now regularly convene state agency heads in pursuit of better coordination and integration, perhaps leading to significant structural changes. In first-wave thinking, structural changes and new policies at the top "trickle down" through top-level supervisors and middle managers, ultimately changing and improving front-line practice.

\section{Second Wave}

The second wave came later. It accompanied the reinvention of government and the devolution of authority and responsibility. ${ }^{2}$ Whereas the first wave was top-down, the second wave was bottom-up. Second-wave initiatives developed because of the limitations associated with "trickle-down

\footnotetext{
2 Then, as now, the principle of subsidiarity was invoked. The core idea is to devolve responsibility and accountability to the lowest levels of government and to invest localities with power and authority.
} 
thinking." Front-line practitioners, whether working alone or in teams structured by top-down mandates, did not receive all of the information and assistance they needed, nor did they always understand and accept what they heard and learned. Moreover, problems related to effective bottom-up communication channels impeded service integration and systems change initiatives, including the Annie E. Casey Foundation's New Futures initiatives (e.g., Annie E. Casey Foundation. 1995; White \& Wehlage, 1995). Although this second wave involved some schools, in reality a limited number were involved. When they were, these pilot schools were part of a grand experiment.

The twin questions for this second wave experiment were as follows.

1. When services are located at, and linked to, schools, does access to service increase?

2. Do these services facilitate early intervention and prevention?

Some so-called full-service schools (e.g., Dryfoos, 1994) developed because of these second wave initiatives. Similarly, a resurgent community schools movement received boosters in this second wave policy context (Melaville \& Blank, 1998).

\section{Third Wave}

We propose three other waves. The third wave already has formed. It began as states developed targeted service integration initiatives. These initiatives were targeted in the sense that they had to be linked to schools. The appealing idea of school-linked services (SLS) is promoted in this wave. (The adjectives "comprehensive" and "integrated" may or may not accompany the descriptions of SLS.) Examples include California (Healthy Start), Missouri (Caring Communities), Utah (Families, Agencies and Communities Together), Kentucky (with school-based youth centers and family resource centers), Indiana (Step Ahead), and New Jersey (the school-based, youth services initiative).

This third wave reflects, and fuels, concerns about the changing conditions of children and families, especially concerns about children's learning readiness. The fullest expression of this concern was stated in the first educational goal for the nation-namely, that all children will enter school ready and able to learn. In response, school-linked services (SLS) were structured to promote learning readiness by addressing barriers to learning and healthy development (Lawson, 1999b). Twin claims were made: (a) that school-linked services were examples of integrated services; and (b) that service providers would collaborate as they integrated services.

\section{Proposed Fourth Wave}

The fourth wave is still forming. It is concerned with expanding the boundaries of school improvement, and especially with incorporating SLS as a vital element in school improvement (e.g., Adelman \& Taylor, 1998; 2000; Corrigan \& Udas, 1996; Franklin \& Streeter, 1996; Hatch, 1998; Honig, Kahne, \& McLaughlin, in press; Lawson, 1999 b \& c; Lawson \& Associates, 1999; Sailor \& Skrtic, 1996; Wynn, Meyer, \& Richards-Schuster, 1999). Similarly, national school reform initiatives include SLS in their structured approaches. Examples include Success for All (e.g., Slavin, Madden, Dolan, \& Wasik, 1996), the School Development Program (e.g., Comer, Haynes, et. al., 1996), schools for the 21st century (e.g., Zigler, 1997), and community schools (e.g., Lawson \& Briar-Lawson, 1997; Melaville \& Blank, 1998).

\section{Proposed Fifth Wave}

The fifth wave is so early in its development that it is barely discernable as a "wave." Because of space limitations, we cannot describe and explain it. We are, however, obliged to introduce it. This fifth wave may be described as the movement to develop comprehensive, neighborhoodand community-based systems of care (e.g., Adams \& Nelson, 1995; Bruner \& Parachini, 1997; Lawson, 2001; McKnight, 1997; O'Looney, 1996). A technical planning framework for service in one sense, in reality it is much more comprehensive. It focuses anew on poverty and its companions, especially in identifiable areas plagued by concentrated disadvantage.

In this system of care framework, SLS and communitybased integrated services initiatives, though vital, are not the only important components. Interprofessional collaboration is not the only kind of collaboration needed. For example, natural helpers and professionals learn to collaborate (e.g., People Helping People, 1997). The school is not the only beneficiary.

This fifth wave is focused on revitalizing neighborhood communities, promoting civic engagement, relying on indigenous support and helping systems, and, all in all, promoting strong democracy. In this wave, colleges and universities play pivotal roles in fostering new approaches to teaching and learning, research, and academically based community service and scholarship. Because this wave promotes such broad community engagement, it is associated with the concept of community collaboration and with university-school-community-family partnerships (Benson \& Harkavy, 1997; Himmelman, 1996; Lawson \& Barkdull, 2001; Lawson, in press a; O'Looney, 1996; Sailor, in press), and with the emerging concept of the "civic professional" (Skrtic, 2000). 


\section{Continuing Lack of Agreement on Meanings and Functions}

The five waves described are evidence in support of an important claim: Although some basic consensus may be developing, disagreements and confusion surround service integration and its companion concepts (e.g., Hooper-Briar \& Lawson, 1994; O'Looney, 1996). As conflicts surface, stress often increases and disenchantment tends to grow.

Gerry (in press) has chronicled some of the differences that pose conflicts. His list of alternative (and perhaps competing) purposes include: (1) improving the service system; (2) maximizing the efficient use of limited resources; ${ }^{3}$ (3) maximizing the independence of families by freeing them from long-term dependence on the government; (4) rebuilding and restoring the capacities of families and local communities; (5) expanding economic and social development and increasing parental employment; and, (6) improving outcomes for children and families.

We suggest three additional purposes: (7) contributing to improvements in school performance; (8) improving professionals' working conditions, efficacy, performance, and job satisfaction: and, (9) revitalizing and empowering local neighborhood communities to mobilize effectively for collective action and to facilitate democratic participation. As if these nine alternatives are not enough, one or more of them can be combined to create others.

In brief, service integration continues to evolve, and predictable challenges and needs accompany its five waves. To reiterate, diverse advocates frequently use the same words, but often they are employing various definitions and promoting different functions. Basic problems such as these constrain well intended efforts.

Furthermore, some definitions, which were offered early in the development of integrated services, may have outlived their usefulness. Recent revolutionary policy changes identified toward the end of our analysis reveal the limitations of earlier thinking about service integration. For example. some early advocates for service integration viewed interprofessional collaboration as its synonym. As a result, disproportionate emphasis has been placed on the formation of team and team-related dynamics. A nearly singular focus on teams and issues surrounding who should serve on them and how they should operate may substitute for a focus on the actual services, including what qualifies as a service, the quality of service delivery, and, indeed, spurious assumptions about the people targeted for services.

\footnotetext{
${ }^{3}$ The case can be made that cost containment and reduction are the twin driving forces behind many service integration initiatives. In this economic calculus, these initiatives are key strategies for the down-sizing of the weltare state. Here, the weltare state is being transformed into the competition state-"lean and mean" and ready for the demands of the global economy (e.g., Lawson, in press b)
}

\section{INTRODUCING INTERPROFESSIONAL COLLABORATION}

For many proponents of service integration, the problem is not so much one of specialization per se. The problem is one of restructuring organizations and their relationships to orchestrate the work performances of specialized professions. Using this logic, it is assumed that when the performances of diverse, specialized professionals are orchestrated, duplication and fragmentation will be eliminated. In turn, access to services, the quality of services, and results will improve.

Reflecting this main assumption about the need to orchestrate the work of diverse, specialized professionals, the concept of interprofessional collaboration usually accompanies service integration (e.g., Hooper-Briar \& Lawson, 1994; O'Looney, 1996). Unfortunately, this concept of interprofessional collaboration also has become a buzzword, and, as such, it may not offer any more clarity than service integration. Often one buzzword is used to define the other.

For example, professionals may be led to believe that, merely by collaborating, they are integrating services. If practitioners communicate better, if their offices are moved to the same building, if they have tried to coordinate their efforts, and if they use the language of collaboration, services are being integrated. Similarly, when professionals claim that they are integrating services, they also may assume that they are collaborating. As a case in point, consider service providers' and educators' responses to two basic questions (Lawson \& Briar-Lawson, 1997).
Q: What's new and different here?
A: We're collaborating and integrating services.
Q: How are things different and better?
A: We're collaborating and integrating services.

Patterns like this one are predictable when the practical, learning, and development-oriented dimensions of collaborating and integrating services are ignored. Here, everyone assumes that merely by announcing them both, interprofessional collaboration is occurring as services are being integrated. In these instances, it is easy to escape critical selfexamination and evaluation, and needs for technical assistance are not identified or addressed.

From this perspective, our process emphasis is a safeguard against such inviting, self-sealing assumptions because it raises key questions:

Are diverse professionals really collaborating?

What does this process mean to them?

How would you know it if you were to see it?

Does it improve their practices and results?

Are providers, in fact, integrating services? 
What does this process mean to them?

How are their efforts measured?

What are the indicators of effectiveness?

These questions frame the "acid test of practice."

Unfortunately, this important test is not administered when bold proclamations of service integration and its companion buzzwords encourage the quick acceptance of selfsealing assumptions. Although service integration may be announced at a higher level, something entirely different usually is operating closer to the ground. Familiar orientations and well established routines endure as part of the deep structures of schools and community health and socialservice agencies alike.

\section{Grand Visions and Two More Buzzwords}

As they promote service integration, some leaders operating at higher organizational and policy levels often have in mind grand visions. At the very least, they envision better inter-system relationships, more personalized attention to each child and family, and better stewarding across professional, organizational, and systemic boundaries. Frequently, these leaders describe inter-system gaps, gulfs, and cracks, which often become permanent homes for "crossover kids" and multi-system families.

At the very least, these cracks have to be filled, and the gaps and gulfs have to be bridged. For them, service integration and its companion concepts serve to fill the cracks and bridge the gulfs and gaps. As cracks are filled and gaps are bridged, inter-system relations improve, and so should efficiency and effectiveness.

Professions' power and authority, however, remain essentially unchallenged in this new system of relations. The core ideas of professional and client remain, along with the power of professionals to define the very needs they address, creating clients in the process (e.g., Cowger, 1998; Lawson, 2001; McKnight, 1995). ${ }^{4}$

At least two cautions follow. If the basic assumptions underlying the service system are flawed, then this approach to systems change; i.e., via interprofessional collaboration and service integration, is not likely to address most of these root problems (e.g., Gardner, 1994; Mitchell \& Scott, 1994). This approach to systems change, then, may not yield improved results. Indeed, this is why critics have been quick to point out that, as long as professions exclusively control the service system, assuming that "professionals know best" and effectively ruling out lay knowledge and indigenous

\footnotetext{
${ }^{4}$ For example. most professionals rail at the proposals offered by $\mathrm{McK}$ night (1995) and Gerry (in press). Both propose giving neighborhood community leaders and their associations the funds now designated for the professions, allowing local residents to determine what they want and need. along with who will provide it.
}

solutions, systems change will not occur. So the second caution concerns the selectivity and silences in the interprofessional collaboration and service integration approach.

Certainly some leaders envision something more than building inter-system relations, and they promote changes in the professions' power relations. Consistent with the meanings of the word "integration," for these leaders service integration implies a complex whole that derives from many specialized parts formed by the various professions and their respective, specialized services. In this view, the whole is greater than the sum of the parts. This whole connotes, for some proponents, an entirely new service system. They use the "systems change" buzzword to describe it.

Integration connotes action verbs such as blending, melding, unifying, and joining. The language for practice follows suit. It includes sensitizing and generative ideas such as seamless services, wraparound services, comprehensive, coordinated case management, and holistic services. Alternatively, a market orientation guides this work, and when it does, the language reflects the logic of the market and economic exchanges. Service integration means one-stop shopping, made possible when providers move their offices to one place (called co-locating providers and services). Similarly, emphasis is placed on determining customers' satisfaction and consumers' needs (e.g., Gardner, 1999). Others emphasize consumer-guided services to ensure that they are responsive, tailored, and more effective. In fact, these advocates for a new consumerism also promote consumer-delivered strategies, along with new careers for former clients in the social and health services and in schools (e.g., AlamedaLawson \& Lawson, 2000; Briar-Lawson \& Drews, 1998).

Systems change is the buzzword used to describe complex changes like these as they occur in any one system such as child welfare or juvenile justice. When all of the professions, their respective organizations, and their governmental sectors are involved, systems change often is accompanied by a sister concept-cross-systems change.

Grand visions like this one regarding systems and crosssystems change provide an important reminder for educators, social and health service professionals, and other readers whose interests are focused on schools. These service integration and interprofessional collaboration initiatives are not limited to schools.

To the contrary, the service integration ideal is being promoted in many neighborhood and community settings. In some ways, interprofessional collaboration and service integration are part of a grand, evolving experiment regarding how human needs can be met effectively and efficiently, and how the responsibilities of government can be determined in relation to these needs. In some people's minds, the socalled reinvention of government also includes the reinvention of the service system, including a fresh, perhaps harsher, 
determination of governments' responsibilities to vulnerable citizens. When competing political ideologies and agendas operate, as they so often do, some of the issues get muddled.

\section{Multi-sector Initiatives}

This much is clear. Interprofessional collaboration and service integration are being promoted in a variety of settings and for a variety of reasons. For example, in healthcare settings such as hospitals, community health centers, and medical clinics, physicians, nurses, social workers, pharmacists, and other professionals claim to collaborate to integrate services (e.g., American Academy of Pediatrics, 1994). In child welfare, social workers, domestic violence counselors, lawyers and judges, substance-abuse professionals, and others often are involved with the same family (e.g., Briar-Lawson. Lawson, Petersen, et al., 1999), and neighborhood-based child-welfare teams also engage in early intervention and prevention initiatives (e.g.. Van Wagoner, Boyer, Wisen, Ashton, \& Lawson, 2001). The language of collaboration and service integration is gaining popularity in child welfare.

Similarly, efforts to promote interprofessional collaboration and service integration have been underway in community mental health systems (e.g., Bickman, 1996; Caplan \& Caplan, 2000). They also are evident in juvenile justice systems (e.g., Cocozza \& Skowya, 2000), as well as in early childhood education initiatives and prenatal programs (e.g., Kagan, Goffin, Golum, \& Pritchard, 1995). Professionals working with populations with developmental disabilities and challenges, including children and youth in special education, also are endeavoring to integrate services and collaborate (Sailor, it press, Sailor, Kleinhammer-Tramill, Skrtic, and Oas, 1996). And with the enactment of Temporary Assistance to Needy Families (TANF), with its work-related and self-sufficiency requirements, interprofessional collaboration among adult educators, vocational counselors, incomesupport specialists, substance-abuse counselors, disability specialists, and other professionals has become more common in public sector welfare programs (e.g., Sandfort, 1999).

As if these sector-specific initiatives were not enough, there are cross-system initiatives. For example, some involve "crossover kids" - children and youth in mental health, special education, juvenile justice, and child welfare (e.g., Kamradt, 2000), sometimes including kids with important medical needs that are not addressed.

In this broad context, it makes sense, for planning purposes, to separate some facets of this growing movement for service integration and interprofessional collaboration from the work of educators and schools. It also is prudent to make distinctions between service integration and interprofessional collaboration. Although the case can be made that service integration and collaboration are interdependent (e.g., Hooper-Briar \& Lawson, 1994; Lawson \& Barkdull, 2001; O'Looney, 1996), they often are defined and implemented separately in real-world practice settings.

For example, as desirable as collaboration may be, professionals may not engage in it. They may try to integrate services merely by communicating more effectively. Similarly, professionals can selectively define "collaboration" as involving more effective communication and cooperation (e.g., Quinn \& Cumblad, 1994). In this case, they may or may not be integrating services.

Everyone who studies integrated services and interprofessional collaboration, like all of the people charged with implementing them in practice, confronts messy situations like these. It is impossible to avoid them. In fact, when we alert readers to these messy situations and the challenges they pose, we are working toward the achievement of the four goals for our analysis. If there are needs to foster shared meaning and understanding, to enable self-directed learning, to promote improved policies and practices, and, to contribute to improved results, there is no choice.

We must ground our analysis in current practice situations-in what Schön (1983) characterized as the swamplands of practice. Well intentioned professionals will not be able to get out of these swamps unless the constraints of their swamps are clearly identified. Once they see their situations as swamps, they need more concrete, desirable, and effective alternatives. And they must be given change- and learning-related improvement frameworks that enable them to get to where they want, and need, to be in relation to their respective swamplands.

\section{DEFINING SERVICE INTEGRATION AND INTERPROFESSIONAL COLLABORATION}

Clearly, in today's context, there are clear and ever-present needs for effective working definitions. Researchers and practitioners alike need precise, concrete answers to three basic, practical questions.

1. How would you know it if you saw it?

2. How would you know if you were doing good work?

3. If you have not achieved the results you need, what do you need to keep doing, stop doing, and start doing?

Although working definitions may not provide all of the answers to these three questions, they mark a good beginning. But a basic problem remains: All definitions are unavoidably selective, and ours are no exception. We begin with service integration. 


\section{Service Integration Defined}

Gerry (in press) has suggested that service integration initiatives can be described in relation to one or more of four basic features. We have added thre . uuve. These seven features are like building blocks for a working definition.

1. Operational definitions of "the problem," including what is wrong that needs fixing, and what is good and right that needs to be maintained and strengtheneds

2. The populations being served, especially targeted populations

3. The types of services, programs, and supports offered

4. The locus of service coordination

5. The kinds of strategies used to link and coordinate services

6. The nature of governance structures and processes

7. How lead responsibility is assigned and how accountability is determined.

To foreshadow a key part of our analysis, educators, special educators, and student support professionals may have limited views of SLS, service integration, populations in need, and the nature of their needs. The school's accountabilities and educators' responsibilities structure these views. In contrast to these school-oriented views of SLS, the vast majority of service integration initiatives are focused on the needs of children, youth, families, and their local neighborhood communities. Poverty and its correlates often are implicated in the conception of the problem.

Although these service integration initiatives often include special-needs children in the special education system, they are not limited to these children. Nor are these service integration initiatives limited to psychotherapeutic interventions. A growing number of service integration initiatives include job and income supports, along with broader community economic and social development programs.

These broader service-integration initiatives also include interorganizational relationships, which may be described as interorganizational collaboration (Lawson \& Barkdull, 2001). These new organizational relationships involve the development of tightly coupled organizations in substitution for uncoupled, or loosely coupled, organizations (e.g., O'Looney, 1996, Skrtic \& Sailor, 1996). At the same time, these broader service integration initiatives may focus on partnerships among private and public sector organizations. Most also include provisions for changes in government agencies. Our definition of integrated services belongs in

\footnotetext{
'In practice, these definitions often are implicit. Both practice and research will improve as each site's "theory, or theories, of the problem" are made explicit and interventions are planned to fit the problem.
}

this broad context; it incorporates three key phrases from Gerry's (in press) definition.

\begin{abstract}
Service integration is a set of strategies by which a community seeks to ensure that all of its residents enjoy immediate, uninterrupted access to children's services, adult services. and family services. Both residents and professionals qualify as service providers. Integration demands that all services are personalized and caring. Where co-occurring needs are evident, service providers coordinate their efforts, and they treat individuals and families in need as partners. Working together, service providers tailor their services to fit what children, parents, and families want and need. Where children are concerned, service integration seeks to optimize the cognitive, social, emotional, and physical development of each child, while simultaneously supporting and strengthening families and enhancing the security and safety of their neighborhood community. Service integration includes job training and supports in service of greater economic selfsufficiency for families. It includes blended approaches to community economic and social development. Finally, it promotes empowerment strategies that enable individuals, groups. and entire communities to mobilize effectively for collective action and for democratic participation.
\end{abstract}

This definition of service integration is new, in some important respects, and it is more comprehensive than other definitions. Although our definition incorporates many of the familiar requirements for effective practice, it also suggests new ones. Unfortunately, we cannot explore with our readers all of the implications of our definition and its practice requirements; however, we can identify two immediate implications.

The first implication involves the contrast between our definition and claims about full-service schools. When service integration (and integrated services) are defined comprehensively, and when this definition includes the requirement that they be personalized and tailored to fit unique needs, the claim that any school provides the full range of services needed by children, adults, families, and neighborhood communities is suspect.

Furthermore, our definition of integrated services raises the normative question: With our definition of service integration as a guide, should schools try to become full-service organizations? Given our definition, this question is a rhetorical one.

The second implication involves inclusion of local residents and family members as service providers. Here we offer two reminders.

1. Families and neighbors already provide the bulk of services, supports, and resources needed, and delivered, in local communities.

2. The service industry provides abundant opportunities for meaningful employment for local residents.

Local residents often are the keys to effective solutions (e.g., Briar-Lawson \& Drews, 1998). Providing them meaningful 


\section{EXAMPLES OF REQUIREMENTS FOR SERVICE INTEGRATION}

- A single point of entry into all public service systems, and with private-service systems that have contracted to work with public-sector children and families.

- Authority of each organization (e.g., community agency, neighborhood organization, school) to determine eligibility for services.

- Shared intake and outreach procedures and criteria by organizations and their professionals.

- A comprehensive, child- and family-friendly initial assessment and case history protocol.

- Services offered without the child or the family demonstrating proof of harm.

- An advocate for each child or family, who convenes other providers for integrated case planning, management, and evaluation.

- Assurances that each child and family will be treated as a unique case, and that services will be personalized and tailored as needed.

- Safeguards against stereotyping by one or more professionals, resulting in a pattern of fitting the child or the family into the preferred intervention.

- Assessment of co-occurring child and family needs, including the child's and the family's self-assessment.

- Opportunities and supports are plentiful for groups of professionals to convene for problem-identification and problem-solving.

- Clear, well 'understood, and effective procedures for referral and access to services.

- Clear, well understood, and effective communication procedures, channels, and networks.

- Designation of child and family advocates who ensure that children and families do not fall through the cracks because providers assume that referral forms and procedures "speak for themselves."

- General acceptance of the principle of "least intrusive intervention" (of professionals intruding as little as possible into the everyday lives of children and families).

- Clear, well understood, and enforced criteria and procedures for ensuring confidentiality.

- Clear and well understood criteria and procedures for sharing information about a child and a family.

- Clear and well understood criteria and procedures for monitoring progress and evaluating results.

- Clear and well understood criteria and procedures for entering information into public data systems.
- Integrated data and management information systems are harmonized across service sectors (e.g., education, juvenile justice, child welfare).

- Clear, well understood, and routine approaches for examining and addressing pervasive, inequalities based on gender in family systems.

- Clear and well understood procedures for assessing the safety and security of homes, schools, and local neighborhood communities.

- Clear and well understood procedures for helping parents get and maintain jobs and suitable housing.

- Clear, well understood, and developed norms and standards for the care and treatment of children and youth, and for how parents may be helped with their roles with children.

- Clear, well understood, and routine approaches for assessing and improving the well-being of children in the content of their family systems.

- Clear, well understood, and enforced norms and standards regarding parental substance abuse and child abuse and neglect.

- Clear, well understood, and routine approaches for assessing and addressing the special needs of women, including domestic violence, spousal abuse, caregiving roles, income supports, child care, transportation assistance, and occupational development.

- Clear, well understood, and routine approaches for assessing and addressing the racial, ethnic, and cultural particularities of the child, family, and neighborhood community.

- Decategorization (blending) of funding streams and flexible use of funds by frontline professionals.

- Clear, well understood, and routine approaches to assigning individuals, professions, and agencies lead responsibilities for addressing a need or solving a problem.

- Performance-based accountability systems allowing flexibility and discretion replace rigid rule- and compliancebased systems.

- Clear, well understood, and routine procedures by which front-line professionals communicate needs for policy amendments and changes to middle managers and top level supervisors. 
employment, along with career advancement ladders, is an important way to stabilize families, strengthen local neighborhood communities, and contribute to school improvement (e.g., Haveman \& Wolfe, 1995; Feikema, Segalavich, \& Jeffries, 1997: Keith. 1996).

\section{Interprofessional Collaboration Defined}

For services to be integrated, professionals serving the same people and communities have to stop working at cross-purposes. At the very least, they need to communicate better, coordinate their efforts, and cooperate effectively. ${ }^{6}$ From this perspective, the idea of interprofessional collaboration can be introduced simply and clearly. Every professional working with the same child, adult, and family has to be "on the same page."

But a basic question remains. Why bother? In response to this question, we provide five interrelated sensitizing concepts.

\section{Interdependence}

The first concept, interdependence, is manifested in the following ways:

1. Children's well-being depends on their peer relations and networks, families, and community systems.

2. In contrast to the system of profession's categorical assumptions, human needs and problems cannot be neatly isolated. Social-ecological analyses have emphasized that human needs and problems often nest in each other. Find one (e.g., substance abuse), and sooner or later, you may find others (e.g., mental health needs, domestic violence, child abuse and neglect).

These interdependent, co-occurring needs are especially challenging to the system of professions. They make it difficult, if not impossible, to effectively address one need unless the others also are addressed (e.g., Briar-Lawson, Lawson, et. al., 1999; Lawson \& Barkdull, 2001).

As a result, the professions depend on each other. That is, any one profession (and its organization) is not likely to achieve its goals and meet its accountability requirements without the assistance and support of the other professions (and their organizations). To put it another way, when humans depend on their peer networks, families, and community systems, and when human needs and problems cooccur and nest in each other, the specialized professions and their work organizations also are interdependent. Each requires the others in order to succeed.

\footnotetext{
"For working definitions of these "c-words" related to collaboration, see Mattessich and Monsey (1992); Winer and Ray (2000); and Lawson and Barkdull (2001).
}

\section{Conditional Equality}

The second concept is conditional equality. Power, authority, and expertise are shared, and democratic relationships prevail. Mindful of their interdependence, everyone, including individuals and families in need, knows that they are either part of the problem or part of the solution. All know that they are "in the same boat."

\section{Unity of Purpose}

The third concept, unity of purpose, is grounded in an understanding of interdependent relationships, and it is a unique feature of collaboration. It also might be called the "neglected feature." For example, when professionals colocate in the same place, they are able to communicate better and their working relationships may improve, but they may not develop unity of purpose. They can coordinate their efforts, sharing the same forms and information systems and addressing confidentiality issues, but they need not develop unity of purpose.

Unity of purpose is evident when professionals truly understand their interdependence and engage in holistic planning. Instead of viewing each child or family narrowly, in relation to the specialized need or problem that their own profession addresses, professionals are concerned with the whole child and the entire family system. Each is equally concerned with every aspect of a child's or a family's wellbeing. ${ }^{7}$ These professionals' shared concern does not mean that they deny, or sacrifice, their special expertise. To the contrary, needs and problems are assigned to them based on their special expertise. The most appropriate professional (the one whose specialization corresponds to the need) is assigned lead responsibility for addressing a risk factor, or for meeting a need.

For example, the classroom teacher may identify signs of child abuse and neglect, but she cannot be expected to address this problem. A social worker with expertise about abuse and neglect assumes lead responsibility for addressing it. Yet, the teacher is no less concerned because lead responsibility has been assumed by, or delegated to, the social worker. The teacher knows that she will not be successful and that the child will not be successful in her classroom unless the social worker also is successful in her efforts to ensure the child's safety and security. The teacher thus celebrates the social worker's success, and reciprocally the social worker celebrates when the teacher succeeds. Unity of purpose is expressed in basic, important interactions like these. It is a key, defining feature of collaboration.

\footnotetext{
${ }^{7}$ Alternatively, when risk and protective factors substitute for well-being in the planning framework, each professional is equally concerned with a child's overall risk and protective factor profile.
} 


\section{Shared Responsibility for Results}

When unity of purpose has been achieved, professionals assume shared responsibility for results (e.g., Gardner, 1999; Lawson \& Barkdull, 2001). This focus on improving results includes related activities such as progress charting, learning and improvement systems designs, and barrier busting. This results orientation, framed by unity of purpose, also guides data-gathering and the development of data systems. including practitioners' action research methods. Absent a focus on results, data systems are aimless, and the data seds are meaningless.

With unity of purpose and a focus on results, learning and improvement, through data and data systems, are facilitated. Everyone is more likely to know what data are important; why they are important; how, when, where, and why to collect data; and how to use these data in support of strategic improvements, learning, and capacity-building. They know that these activities are in their best interests, as well as in the interests of those they serve.

\section{Enlightened Self-Interest}

Accordingly, the fifth sensitizing concept is enlightened self-interest. At first this concept may seem crass because many conversations about collaboration convey the impression that everyone should put aside their specialized needs and interests. In this environment, it may not be safe to ask and answer two basic, important questions:

1. Why should I (and my agency or school) participate in this collaborative work?

2. What's in it for me and us?

For a host of reasons, questions like these are viewed as the opposite of collaboration, and people who insist on asking them may be perceived as selfish and unprepared to collaborate (Lawson \& Barkdull, 2001). When that environment prevails, and when people are unable to ask and address these questions, collaboration is constrained, limited, and perhaps prevented. Busy people with excessive workloads and job pressures simply cannot be expected to attend meetings and participate genuinely unless they have good reason to believe that their attendance and participation will improve their jobs and lead to improved results. So, when professionals acknowledge their interdependence and agree to collaborate to improve results, they are enlightened because they know that, by joining forces, they gain "the collaborative advantage" (e.g., Lawson \& Barkdull, 2001; Sarason \& Lorentz, 1998).

Enlightened self-interest also means that every professional has a stake in this collaborative undertaking. Various stakeholders agree to collaborate, and their collaboration is sustained as long as it benefits them. Collaboration of this kind is a voluntary activity, and it requires willing participants. Although meetings can be mandated, true collaboration cannot be forced. Interprofessional collaboration is not done to people, or for them-it is done by them (e.g., Himmelman, 1996).

\section{Reciprocity}

The sixth sensitizing concept is reciprocity. When professionals collaborate because they cannot achieve their goals unless they do, and when they do so as a matter of enlightened self-interest, they are more willing to give and share as well as to receive. Reciprocity implies mutuality, and mutuality means developing common grounds for working together.

Reciprocity also suggests an exchange system built on these common grounds. In this sense, interprofessional collaboration is a reciprocal exchange relationship. I help and support you while you help and support me and us. Each successful exchange builds on the others.

Over time, strong social trust networks develop around task-focused work. In the process, former strangers and competitors become acquaintances, colleagues, and even close friends. Reciprocity emphasizes the importance of social and cultural bonding and networking, which derive from successful task completion and joint problem-solving. True collaboratives tend to become vibrant communities of practice (e.g., Wenger, 1999).

\begin{abstract}
Interprofessional collaboration occurs when two or more professions join forces and develop unity of purpose to improve results. It occurs when (and because) they depend on each other to achieve their goals and meet their accountability standards. When professionals truly collaborate, they do because they understand their interdependence; they view collaboration as part of enlightened self-interest; and they promote and reward reciprocity.

Professionals who collaborate share missions, goals, and objectives. They also share definitions of "the problem(s)," including what's wrong that needs fixing and what's good and right that needs strengthening. They develop shared language, problem-solving protocols, and barrier-busting strategies. They also learn to share resources, supports. They develop shared governance structures. Thus, true interprofessional collaboration is durable; it tends to have sticking power and staying power.
\end{abstract}

\section{Generativity}

Generativity is the seventh concept. True collaboratives generate creative, innovative approaches to the theory of the problem and to intervention and improvement strategies. They also generate learning, development, and systems change in relation to professional and organizational boundaries and boundary relationships. Last, but not least, when collaboratives become communities of practice they generate affective commitments and identity changes. Effective and appropriate collaboration changes people's lives, not 
just their jobs.

Defined in this way, interprofessional collaboration is grounded in firm ethical-moral imperatives. It is a best-practice strategy, and at times it may be the only way to improve results for people in need-to truly serve them.

The basic requirements for collaboration are:

- Reasonable people who are able to listen, learn, compromise, adjust, and adapt.

- Collaborative, interprofessional leaders and facilitators who are able to cross professional, community, and organizational boundaries and build relationships.

- Norms that prevent blame and maltreatment dynamics and improve the quality of mutual treatment and interaction.

- Special settings (places and environments) that support joint performances, learning, and development.

- Supportive organizational climates and structures.

- Organizational incentives, rewards, supports, and resources for joint work and ventures.

- Special governance structures and processes (e.g.. school-community planning teams).

- Communicative and linkage mechanisms for the various professionals and for their organizations.

The complexity increases when the third part of our title is added to the mix: developing connections with schools. In short, instead of just two challenges (integrating services and collaborating), there are three. Although developing these connections in a strategic and effective way can be difficult in its own right, maintaining these connections may be even harder. Even when some service providers have established connections with schools, these connections are not necessarily evidence of either service integration or interprofessional collaboration.

\section{Confusing Connections}

Presently, some community services may be linked to schools already, but they are not necessarily integrated. Often, community service providers respond only to specialized needs identified by the school. For example, a social worker may respond to calls regarding child abuse and neglect. Or a substance-abuse counselor may respond to a call about an adolescent's drug problem. Especially in large schools, these two professionals may not be aware of each other.

Even if community service providers are made aware of each other, and they are encouraged to collaborate to integrate their services, there is simply too much going on in their professional lives to expect too much, too fast. At the same time, they are trying to figure out whether to collaborate and integrate services, they must learn how to do them both. And still the third challenge remains. They also must decide whether, and how, to develop strategic, effective connections to schools. And then they must figure out, with educators, how to maintain these connections. None of this work is easy.

The work becomes even more complicated when important people at the school are omitted from planning and policy discussions. Consistent with third-wave thinking, many SLS initiatives involve only social and health service professionals from the community. In short, the growing SLS movement often has ignored a fact obvious to anyone who knows schools: Schools have their own collection of social and health service providers, including school nurses, speech and language therapists, physical and occupational therapists, social workers, counselors, and psychologists. Once this reminder is provided, the work of developing connections gains importance.

Even if services are being integrated in the community, they may not be connected to, or integrated with, the school's pupil support professionals. Nor are some communityoriented SLS initiatives connected with special educators, or with the school's classroom teachers (e.g., Adelman \& Taylor, 1998; 2000; Lawson, 1999 b \& c). Once this fact is entertained, intra-school challenges related to collaborating, integrating, and making connections also are evident.

Despite an emphasis on school-based collaboration (e.g., Christiansen, Goulet, Krentz, \& Maeers, 1997), especially in relation to special education children and youth (Sailor, 1991; in press), each school's pupil support professionals' services, special educators' work and classroom teachers' efforts are not automatically connected or integrated. Nor do these school-based professionals and educators automatically collaborate. For example, in large, highly challenged, low-performing urban schools, staff turnover alone makes mutual awareness and understanding the real challenge. Collaboration, if it ever results, comes later.

\section{PLANNING FOR COMPLEX CHANGE}

A complex change initiative is formed when the three process elements are joined: integrating services, collaborating, and developing connections with schools. Complex change and its orchestration pose considerable challenges (e.g., Lawson, 1999a). Despite these challenges, there are good reasons for proceeding. In our view, collaborating, integrating, and connecting practices are a good thing to do; and they are the right thing to do. Done right, they promise help and supports for children, youth, families, and professionals. Done right, this triumvirate of practices also will improve schools, help children, support families, and strengthen their neighborhood communities.

Given competing definitions of integrated services and its companion concepts, however, questions remain: What does it mean to do it right? Is there just one definition? Who 
decides? Who decides who decides?

These questions involve basic, important issues regarding purpose, vested interests, power, and authority. Often they serve to divide good people who need to become united. Place matters. That is, these questions are framed by local people, contexts, and cultures (e.g., Armstrong, 1997; Foster-Fishman, Salem, et. al., 1999). And just because they were considered and answered at one point in time, there is no guarantee that they will be addressed in the same way later. With time, fresh awareness, and changing circumstances, they may be addressed differently. There is simply no way to deny and avoid the complexity of the post-modern age (Skrtic \& Sailor, 1996).

\section{The Import of Our Process Emphasis}

In the post-modern era, one size fits few. Mindful of unprecedented variability, complexity, novelty, and uncertainty, we have provided a process emphasis, along with a toughminded focus on results. This process emphasis is justified because the work associated with integrating, collaborating and developing connections is never finished. After all, human needs and societal problems change. New policies often create new needs. Furthermore, this work is neverending because, over time, people come and go. Veterans, especially leaders, leave, while newcomers join. Our process emphasis gives due recognition to these basic realities.

Furthermore, our process emphasis also may act as a safeguard against self-congratulatory and self-sealing patterns. It forces difficult questions rather than accepting at face value what people and their organizations proclaim about themselves, or have announced in their behalf. And, because it encourages planners and analysts to ask the most basic, practical questions, it helps identify important needs for technical assistance, education, and training, and capacity-building. Identifying these needs is a key benefit.

Despite its advantages, our process orientation is not a panacea. For example, two ever-present dangers loom when people focus on these three processes.

\section{Lost in the Process}

The first danger is evident when professionals become so preoccupied with integrating services, collaborating, and developing connections with schools that they forget that these processes are strategies (means), not goals (ends). This is the familiar problem of goal displacement, which is also called an ends-means inversion. When new strategies, or means, become ends or goals in their own right, significant problems result.

In brief, our process emphasis should not be viewed in any of the following ways: It is not a justification for collaboration because it enables professionals to make new friends, for service integration for its own sake, or for mak- ing connections with schools as a productive leisure pursuit. Rather, we view integrating services, collaborating, and developing connections as essential best-practice strategies. They are essential means to other ends-improved results.

\section{Linear Change and the Categorization of Each Process Component}

A second danger introduces an irony. When people view the change process as linear, and when they take an extreme view of the differences among the three processes of integrating, collaborating, and developing connections, they effectively undermine the basic purposes of the service integration movement. Simply stated, they make each process (e.g., integrating) a hard-and-fast category. Because of their linear view of the change process, they place each process category in a step-wise progression. In other words, these linear, categorical views of change foster a "one at a time" line of thinking. Reflecting this orientation, well intentioned people describe change as occurring in steps.

Step one: The various professions have to learn how to collaborate.

Step two: They have to integrate services.

Step three: They have to make connections with schools.

Here, the lessons of the first three waves of service integration are instructive. This linear, categorical approach takes years. It also overlooks the fact that the work of integrating, collaborating, and developing connections is never finished. More to the point, by the time the third step is anywhere near someone's definition of completion, another generation of children (and their families) has had to endure needs without the help and supports that professionals could have provided. In this linear, categorical approach, professionals from all walks of life themselves do not receive the mutual supports they need and deserve.

With these limitations in mind, our process-oriented approach promotes a non-linear approach to change. Change, in this view, proceeds in interacting phases, not in linear steps (e.g., Lawson, 1999a). In contrast to "one at a time" thinking, the advantage of this approach is that several beneficial processes can be launched simultaneously, effectively reducing the time needed to see progress and improve results. Unfortunately, this non-linear, multi-phasic approach to change is associated more with the fifth wave of service integration than it is to waves three and four.

\section{THIRD-WAVE THINKING: CHILDREN AND YOUTH READY AND ABLE TO LEARN}

Third-wave thinking continues to dominate SLS planning and operations. States have supported targeted SLS ini- 
tiatives for several related reasons. Two are especially relevant. SLS initiatives are one response to America's changing demographic profile, especially the characteristics of its children and families (e.g., Cappella \& Larner, 1999). Because more children and families evidence vulnerability and needs, SLS initiatives, in essence, perform double duty. SLS may meet these needs at the same time that they enable children and youth to enter school ready and able to learn. Using this logic, schools are supported and will improve.

A dominant "theory of the problem" can be derived from third•wave thinking (Lawson, 1999b \& c). The real problem is with the learning readiness and healthy development of children and youth, in turn implicating parental and family needs. Once these needs are addressed, schools will be effective. This thinking thrusts responsibility for meeting these needs onto families and, of course, on school-linked social and health service providers. In this view, SLS is a challenge for service providers, especially communitybased social and health service providers. Teachers need not be concerned or directly involved.

In this context, educators have viewed service integration in general, and SLS in particular, as serving them. Educators view SLS, in essence, as a one-way exchange system. The problem is not with them and the school (e.g., Gardner, 1994). A "fix, then teach" approach reigns (e.g., Honig, Kahne, \& McLaughlin, in press). Educators thus are inclined to blame service providers and parents when children and youth come to school, not ready and able to learn. When service providers and parents do not do their jobs, educators have trouble with theirs.

Meanwhile, community health and social service providers, some parents, and community leaders take a different view. In their view, the problem is with the schools. Schools have to be readied to enable the learning, academic achievement, and healthy development of all children and youth. And, just as educators expect service providers to personalize and tailor their services, so, too, do service providers expect educators to personalize and tailor their instruction. For example, some educators are unprepared for growing child and family diversity, including the challenges of inclusive education.

Just as service providers may typecast children and families and provide routine, preferred services, so, too, do some teachers typecast children and youth in their classes and use routine, preferred teaching and instructional strategies. When educators do not do their jobs, service providers have trouble with theirs. After all, school problems are associated-with, and may even cause, substance abuse, delinquency and crime, family stress, domestic violence, and other personal-social problems. So, while educators may be blaming them, service providers may be blaming educators.

In a nutshell, there are mutual blame and maltreatment dynamics here (Lawson \& Briar-Lawson, 1997), and these dynamics are among the most important barriers to mutual understanding and effective collaboration. They help harden the categories. Instruction and teaching belong to teachers, and they occur in classrooms. Service delivery belongs to social and health service providers, and it occurs in their oftices.

Teachers may not benefit from having service providers in their classrooms and gaining access to new pedagogical strategies (e.g., Mooney, Kline, \& Davoren; 1999), and service providers may not benefit by having classroom teachers serve on their teams. No wonder academic achievement may not improve significantly when SLS initiatives are implemented. The social arrangements work against the most important requirements for collaboration, especially unity of purpose.

Principals' jobs become more complicated with thirdwave initiatives. Principals are involved because providers may wish to relocate at their schools, and a host of new challenges arise when office space must be provided. This relocation (also called co-location) often constitutes what some analysts call school-based services and, perhaps, full-service schools and community schools. ${ }^{8}$ Moreover, student support professionals and special educators also must be involved, if for no other reason than to protect their jobs and prevent unnecessary competition and conflicts.

\section{Three Focal Points}

Although Howard Adelman and Linda Taylor (1998, 2000) are among the leaders of what we call "fourth wave," their work spans third- and fourth-wave thinking. Arguably, their interprofessional frameworks for SLS are the clearest and most precise.

Mindful of the problems and conflicts that result when state- and community-sponsored SLS initiatives are proclaimed without taking into account the schools' student support professionals, Adelman and Taylor make a key distinction between school-owned and community-owned services (and related resources). They correctly assert that planning must focus on the relationship between these two kinds of services. Knowing that in the most vulnerable communities, qualified professionals will remain in short supply, and seeking greater efficiency and effectiveness, Adelman and Taylor have provided clear guidelines and useful assessment inventories. Adelman and Taylor (1998, 2000) also have developed an elaborate planning framework for coor-

\footnotetext{
${ }^{8}$ Thanks to the work of a National Coalition for Community Schools, consensus is growing about new kinds of schools that incorporate many different components. Past-present differences, however, can be identified among full-service schools, community schools, and full-service community schools (e.g., Lawson, 1999c). These differences are important because they provide choices.
} 
dinating, harmonizing, and synchronizing, school-owned services and community-owned services. We commend their work to readers.

The second key point marks a departure from the full-service school. In lieu of expecting just one school to provide all of the services, entire feeder patterns are a more appropriate unit of analysis. Here, too, Adelman and Taylor (1997 a \& b) have provided important leadership. The core idea is that services have to be articulated across P-12 in the same way that school subjects are.

The third focal point is related to the first. It entails developing common principles and practices among all of the service providers, whether school-owned and supported or community-owned and supported. Here, SLS initiatives intersect with other, community-based interprofessional collaboration and service integration initiatives (e.g., those in medical clinics and child welfare agencies). The requirements listed earlier may apply directly to the design of SLS. Otherwise, SLS initiatives will be in direct competition with other interprofessional collaboration and service integration initiatives. In fact, "inter-collaborative competition" is already in evidence in several large communities.

With other service providers, SLS providers must make informed choices. They must choose their practice principles and, presumably, their service-delivery orientations from a growing number of alternatives, that list "best-practice principles." Typically these lists provide a kind of shorthand language for service providers. This shorthand includes descriptors such as child-centered, family-focused, empowerment-oriented, culturally sensitive, integrated, collaborative, strengths (asset)-based. solution-focused. and results-oriented. Often they are structured to present a fromto orientation - that is, the "old" principles are contrasted with the "new" principles.

These choices are especially important. But, they are complicated by at least two major factors.

\section{The Buzzword Factor}

The first might be called the "buzzword factor." Because each profession's literature may not provide clarity and precision, and because providers and their agencies have established preferences for service design and delivery, multiple meanings, orientations, and functions accompany these socalled best-practice lists. For example, empowerment has multiple meanings (e.g., Ackerson \& Harrison, 2000). Moreover, one list may emphasize family-focused practice while another emphasizes family-centered practice. Although both feature the family, they entail very different strategies.

In family-focused practice, for example, the child is situated in the context of the family as professionals design and try to integrate services. In family-centered practice, family members enjoy equal power and authority; they are joint designers of services (e.g., Briar-Lawson \& Drews, 1998). In the same vein, significant differences develop when differences among culturally sensitive, culturally relevant, and culturally responsive practices are unpacked. It is not easy to resolve these differences.

In short, as helpful as lists of best-practice principles are, they do not guarantee harmony, synergy, collaboration, and service integration. Third-wave thinking presents another complicating factor.

\section{The School Factor}

The second complicating factor is "the school factor." We explore this one in greater detail after the next section on fourth-wave thinking. For now, suffice it to say that, for many of the school's student support professionals, the shift from student-focused, or child-centered, practices to practices involving families and communities is nothing short of revolutionary. As Tyack (1992) has demonstrated, these school-supported professionals have a long history of working with individual children, at school, to improve their school-related behavior and performances. Providers, then, are at the school in support of the school, its missions, and its accountabilities.

Little wonder, then, that evaluators and policy-makers alike have expected, and looked for, improvements in children's academic achievement as SLS initiatives have been implemented. For a host of reasons, however, these expectations have not been met. Although modest gains have been reported in selected elementary and middle schools-importantly, schools in which teachers often work closely with service providers-SLS alone do not yield impressive, generalizable improvements in children's school achievement (e.g. Wagner, Newman, \& Golan, 1996).

Warren's (1999) superb evaluation of New Jersey's school-based youth services program (SBYS) provides especially significant findings. These findings signal some of the limitations of third-wave thinking and, at the same time, they illuminate important choices and fresh opportunities.

SBYS is primarily an after-school initiative that combines programs and services. It uses recreation and personalsocial support services as "hooks" or "magnets" for youth. Prior evaluations of SBYS had indicated reductions in personal-social problems such as teen pregnancy and substance abuse. Similarly, Warren's evaluation yielded promising data in support of important progress in youth development.

Arguably, one of her two most important findings concerns academic achievement. Warren learned that SBYS successfully attracts youth-youth who might not otherwise come to school, attend, and stay. Because they do not drop out, however, and their academic performances are included in the school's achievement profiles, overall school perfor- 
mance may not improve. Indeed, it may even decline!

Enter Warren's second important finding. Many youth are challenged by poverty and its close companions, as well as by family issues, and neighborhood-related problems. SBYF simply cannot address all of the needs these youth evidence. Many SLS initiatives in other states face the same kinds of challenges.

Key choices and important opportunities thus derive from third-wave thinking and its SLS experiments. For example, trade-offs are involved. Healthy child and youth development as promoted by SLS, including the prevention of school drop-outs, may run counter to expectations about improved performance on academic achievement tests (see also Halpern, 1999a). So is it better to keep children in school, contributing to their learning and healthy development, even if their performance on standardized achievement tests affects the school's overall achievement profile? Opportunities may emanate from trade-offs like this one.

For example, both fourth wave and fifth wave thinking derive from these kinds of trade-offs and related findings about third wave SLS. In fact, the connections among these three waves emerge. Is it possible the third wave thinking is not so much flawed as it is incomplete? In other words, is SLS a necessary, but insufficient. intervention? Furthermore, where are families, family support networks, and indigenous community service, support, and resource systems in third wave approaches to SLS? Where is the private sector, and what importance is placed on jobs and economic development?

Questions like this one are associated with fourth wave and fifth wave thinking. Indeed, our definitions of service integration and interprofessional collaboration indicate our stance in relation to these questions and others.

\section{FOURTH-WAVE THINKING}

Without question, children and youth need to come to school ready and able to learn. However, Goals 2000, like third-wave thinking about SLS, ignored another key goal: Schools have to be readied for the learning and healthy development of all children, youth, and families (Lawson, $1999 \mathrm{~b} \& \mathrm{c})$. If schools are not optimally designed, and if they do not provide optimal environments for children's learning, or for professionals' work, even the best conceived SLS will not result in improvements in the school's academic achievement profile.

In third-wave thinking, SLS are ratcheted onto schools. Real schools, especially their deep structures, are not changed (Tye, 2000; Tyack \& Cuban, 1995).

Fourth-wave thinking proceeds beyond services reform. It is a concerted effort to reinvent American schooling, especially for its most vulnerable populations challenged by poverty and its companions. More than a new approach to schooling and school improvement, this reinvention of the American school is tied to a growing national movement in support of children and their families.

\section{SLS Variations}

Significant differences thus accompany fourth-wave thinking. These SLS differences are important because they provide different cognitive maps for the change targets, the key actors, and the change processes. For example, Lawson (1999c) has identified these different versions of SLS.

- Co-locate service providers and link them to schools to address the needs of at-risk students. Here, the assumption is that children need to be "fixed" so schools can work as planned-the problem is with the children, not with schools.

- Co-locate service providers to help families and adult community members, in addition to children and youth.

- Co-locate and link service providers to schools and make them conform to the requirements of a particular model for school reform (e.g., Comer School Development Plan; Accelerated Schools; Success for All).

- Recast the roles of existing school support professionals for child study and assistance, involving interprofessional case management, school-based resource teams, or both.

- Prepare parent paraprofessionals for service delivery, family support, and community development.

- Use SLS initiatives as the catalyst for broad-based community collaboratives, which are home to SLS but are not limited by them.

- Hybrids formed by combinations of the above alternatives.

Each of the above alternatives is based on different assumptions about "the theory of change, " and each stipulates different responsibilities and roles for teachers, principals. other professionals, and families. Whether a school's, or a school district's, SLS configuration qualifies as either "comprehensive services" or "integrated services" depends on the alternative selected.

\section{Joining Schools, Families, and Communities}

Fourth-wave thinking derives from understanding patterns of interdependence. It takes a social and ecological view of schools, families, and their surrounding community context. Employing the planning frame provided by "the school community" and focusing on "educational reform and renewal," this new line of thinking escapes the limitations associated with the school as a standalone institution in which educators do it all alone (e.g. Lawson \& BriarLawson, 1997). SLS is incorporated into a broader, more 
comprehensive planning framework.

For example, Adelman and Taylor $(1998,2000)$ focus on addressing barriers to children's learning and healthy development to enable learning and success in school. They call their approach "the enabling component," and they identify six enabling areas meriting school and community collaboration.

Similarly, Lawson and his colleagues (e.g., Lawson, 1999c; Lawson \& Briar-Lawson, 1997; Lawson \& Associates, 1999; Lawson \& Barkdull, 2001) also have promoted multiple forms of collaboration. Interprofessional collaboration and SLS are part of this planning frame, but they are not alone. These two important initiatives are accompanied by family-centered collaboration, inter-organizational collaboration, and broad-based community collaboration.

Different in some important respects, these two approaches, like others that are developing, share a simple, yet compelling logic: School improvement and renewal processes are destined to fall short of their intended aims until such time as the family and community contexts for children's learning and development are addressed simultaneously. In other words, start with the factors and forces known to influence and determine children's learning, healthy development, academic achievement, and success in school; and then ask how professionals, parents, and other diverse stakeholders in school communities can work collaboratively to address them. This work entails institutional change involving schools, social and health services and their providers, and their boundary relations.

\section{Interdependence, Enlightened Self-Interest, and Reciprocity .}

At least in the dominant institutional definition, the American public school is a stand-alone organization. It is designed for children and youth. Its purpose is to enable their learning and academic achievement. Educators assume responsibility for this learning and academic achievement, and they are held accountable for them. In this institutional definition, educators and their colleagues located at the school are expected to focus on this special category formed by children's learning and academic achievement, and they also are expected to "do it all, alone." In turn, teachers expect to work in classrooms alone, and external constituencies share this expectation.

Little wonder, then, that so many school reform and improvement proposals emphasize a reduction in class size and perhaps more funding. Nor is it surprising that the overwhelming majority of school improvement proposals focus on changes inside the organizational and institutional box of schools (Lawson, 1999c). The main assumption is clear: Educators can control experiences only inside the schoolhouse walls.

The controversies surrounding the so-called full-service school (Dryfoos, 1994), especially the mixed reviews they receive from professionals and laypersons alike, provide an important case in point. Their criticism is revealing, and it goes something like this.

Schools are for children's learning. Principals and teachers should concern themselves only with teaching as it affects learning. Schools should not be community social and health service organizations. When full-service schools are created, and when schools become the primary service providers, resources are deflected from the school's mission. Principals and other educators, already overloaded, are asked to take on additional responsibilities for which they have not been prepared. The problems of service design and delivery belong to the community, not to the school.

This critique could be offered by anyone who has ever gone to school. Its logic may be called "common sense" about schools. It is evidence of a powerful underlying institutional field. And it suggests that even the best reforms and improvements related to integrating services, collaborating, and developing connections with schools will not last, nor will they penetrate the school's deep structures, unless reformers take into account, and address effectively, the forces associated with these institutional fields.

Paradoxically, anyone who spends a few days in schools and sits down for awhile in the teachers' lounge will hear a familiar lament: "If only I had some influence and control over what this child experiences and does outside my classroom, I could really help him or her succeed." Although it remains unspoken, another important lament accompanies the first one: "And if I did enjoy more influence and control, I'd feel more successful, too." These important laments never get beyond the status of a patterned occupational complaint, even though they signal important opportunities.

Here, five "facts" are embedded in schools, and together they structure the school's institutional field. They form a familiar pattern, one that is viewed as inevitable and "natural."

1. Children spend less than 15 percent of their time in schools.

2. An even smaller portion of this time in schools is devoted to academic learning.

3. Some of the most important influences on learning, academic achievement, success in school, and graduation from high school are rooted in peer networks, families, and community systems.

4. Because educators have little or no influence or control over these extra-school factors and forces, their abilities to produce improvements in learning and academic achievement are destined to remain limited.

5. Educators are caught in double-binds because, even though they do not enjoy much influence and control over some of the most important factors that influence 
and determine learning and academic achievement, they nevertheless are held accountable for them, and they are being judged in relation to their abilities to demonstrate improvements.

This familiar pattern is called a competency trap (e.g., Argyris, 1999). Good people get trapped into believing that their limited success is inevitable and unavoidable, and they are unable to imagine and implement alternatives that get them out of the trap.

Competency traps are dangerous, and they can cause harm. For example, a growing number of teachers and principals are lamenting the gross injustice of being blamed and maltreated when academic achievement and school performance do not improve, when they have little, if any, influence and control over children's lives outside the school. In turn, when feelings of being blamed and unappreciated spread, this affects the retention, morale, and future recruitment of teachers and principals.

Collaboration is needed because no one profession (e.g., educators), or its organization (e.g., the school), can achieve its goals and meet its accountabilities without the supports of other professions (e.g., child welfare professionals, health professionals) and their organizations (e.g., child welfare organizations, community health clinics). Professions and organizations thus collaborate out of practical necessity, reflecting their self-interest. As they develop common grounds, especially unity of purpose, they also develop norms and procedures for reciprocity. For example, the school is served when service providers enable children and youth to come to school ready and able to learn. In turn, service providers are supported and rèinforced when children and youth succeed in school. Each system improves and gets stronger because of its new boundary relationships and exchanges.

In fact, the case is being made that the most important school-related, peer-related, family-related, and community-related factors for improved academic achievement, learning, and success in school are the very same factors that predict success in the child welfare, juvenile justice, mental health, health, and employment sectors (Lawson \& Associates, 1999). The keys to educational improvement and renewal, then, also are the keys to improvements and renewal in other child and family-serving systems. By addressing school-related needs, other systems' needs also can be addressed. Special education professional practices, for example, have implications for persons with disabilities that extend far beyond the confines of educational settings (Sailor, 1996). This is the core idea behind our comprehensive definition of integrated services, our results-orientation for collaboration, and our insistence on making certain that connections with, and at, schools are strategic ones.

A focus on job training for parents and community eco- nomic development will be as new to some service providers as it is to educators, but it is essential. For example, addressing the employment needs and security of a parent lessens family stress and facilitates the work of a child welfare worker. It also helps stabilize families, in turn reducing the school-related transience of children and youth. Furthermore, suitable parental employment is associated with a lower probability of school drop-outs and a higher probability of graduation (e.g., Haveman \& Wolfe, 1995). Focusing strategically on one important areaparental employment-benefits every profession and agency working with the same child and family.

So simple and basic in one sense, this work also is incredibly difficult because it requires new job descriptions and orientations along with supportive organizational structures, cultures, and accountability requirements. For example, interprofessional leadership is essential (Lawson, 1999b; Sailor, in press). Unfortunately, few professionals and community leaders have been prepared for this kind of boundary-spanning and -crossing work. Whatever their name-school-familycommunity coordinators, facilitators, resource coordinators, family advocates, community school coordinators, assistant principals, or more plainly social workers, counselors, and special educators - their functions are much the same. They help orchestrate diverse people, and they help structure school community settings for collaboration. They enable educational reform and renewal because they support principals, teachers, and parents to engage in conjoint problem-solving.

Teachers' roles and responsibilities change, too. For example, they learn to detect risks and needs, work with referral agents and systems, and partner with service providers and parents. The firm dividing line between pedagogy and service integration dissolves, and so do the ethnic and cultural lines that divide a growing number of children and families from teachers, principals, and other professionals.

Principals' roles and responsibilities also change as they and their schools accept new challenges (e.g., Lawson, 1999c). For example:

- Facilities challenges: Although some school facilities have been designed and constructed in response to this emergent prototype (e.g., the Children's Aid Society schools in New York City), in most cases principals and other leaders have had to work within the confines of existing school facilities. Principals must find space for service providers. They also must make sure that facilities used in the non-school hours (e.g., adult eduation, after-school programs for students) are returned to normal after their use. This involves coordinating the work of custodians, service providers, program leaders, and teachers.

- Funding challenges: These challenges include lever- 
aging and, if needed, reallocating Title 1 funds, Title IV-E and Title XIX funds of the Social Security Act, and IDEA funds. Other funding streams also have to be tapped. There is never enough money.

- Supervision and evaluation challenges: As principals' roles are recast, some instructional supervision and evaluation may have to be delegated to mentor teachers and assistant principals.

- Time challenges: Principals will have to delegate and give away some responsibilities to find the time needed to help coordinate all of the people at the school. Teachers initially will express frustration because the principal is not readily available to them. They need to understand why other key people, such as service providers, community leaders, and parents, demand so much time.

- People challenges: People need help in changing their mindsets about themselves and other people, and in changing their "mental models" for schools and school reform. The full-service community school increases people traffic at the school. More people bring more challenges, at least initially. Principals have the lead responsibilities for working out rules, roles, and responsibilities and for promoting positive interactions among people and for ensuring safety and security. Liability issues also have to be ironed out.

- Collaborative leadership: A new style of leadership is required, one that fosters voluntary commitments, develops a sense of empowerment, is results-focused, and relies less on rule enforcement and compliance. Leadership involves new school-community connections and developing cross-school improvement plans with other principals.

- Resource generation and effective utilization: Especially in high-poverty communities, resources are a priority. The principal becomes a key resource-broker. The principal secures new resources and learning supports for the school. In return, the principal offers to community agencies and neighborhood organizations school-related resources that support them.

- Advocacy for children and youth: The principal becomes a tireless, passionate advocate for kids' learning, success in school, and healthy development. This principal is a tone-setter in the school community, helping others set and achieve high performance standards for all children and youth. This advocacy is broad-based and family-centered. In short, the principal is a key leader for the development of Caring School Communities for children and youth.

- Family support: The principal helps other educators and service providers appreciate the need for parents and families to be supported, and they are instrumen- tal in the creation of school-based family resource centers and in the training and employment of parent paraprofessionals.

\section{Benefits to Schools}

So is it worth the effort? Based on his research, Hatch (1998) claims that it is. Here are key examples of the benefits he identified.

- Improvements in the physical conditions and resources that support learning.

- Increases in the number and kinds of people that support learning and the schools.

- Improvements in the attitudes and expectations of parents, teachers, and students.

- Improvements in the depth and quality of the learning experiences in which students, teachers, and parents participate.

Hatch is not alone in documenting these kinds of improvements (e.g., Dryfoos, 1998; Melaville \& Blank, 1998; Schorr, 1997), and we would add two others (Lawson \& Associates, 1999). A "can do" attitude spreads as the individual and collective efficacy of professionals, children, and parents grows, and, as a result, the well-being of professionals, including their job satisfaction, improves. Clearly, all of these benefits and others waiting to be developed, and documented, justify the effort.

\section{POVERTY, SOCIAL EXCLUSION, AND THE FUTURE OF AMERICAN DEMOCRACY}

Children and youth are literally dying for attention. The tragic killing in Littleton, Colorado, like those elsewhere in the nation and in other parts of the world, indicate that children and youth from all walks of life have needs for services, supports, and resources. Where the well-being of the nation's children and youth is concerned, the case can be made for profound governmental and social institutional neglect. Because integrated services, interprofessional collaboration, and new school community connections effectively address this neglect, they are good things to do, and they are the right things to do. Whether they are enough, and whether they are designed to address every important need are separate questions. Service providers and educators alike deserve plaudits for their efforts. They are trying to work together-even to collaborate. Indeed, growing numbers are succeeding.

The fact remains, however, that poverty and its companions remain an important challenge even though "wars on poverty" are apparently out of fashion. Gaps between the very rich and the very poor continue to grow, and the divides between them are separated by place and space dynamics. 
America's cities and some of its poorer rural areas now have identifiable social geographies. Service integration, interprofessional collaboration, and school-community improvement renewal initiatives also have place-based, or social geographic, dimensions (e.g., Briar-Lawson \& Lawson, 1998: Lawson, 1999a).

For example, in an increasing number of cities, urban planners now work closely with service providers. They employ computer-generated geographic information (GIS) surveys, which effectively map personal-social needs. As it turns out, some, postal codes are associated with living in a community characterized as one of "concentrated disadvantage." These communities, evidence disproportionately high child abuse and neglect. school problems, crime and delinquency, unemployment and underemployment, substance abuse, and health and mental health needs. As Sen (1999) notes, the life circumstances and expectancies of citizens in some social geographic areas of American cities are now lower than those in so-called developing nations such as Bangladesh.

Economic globalization, especially the loss of industry and low-skilled jobs, is part of the problem. In these communities. it is difficult to recruit and retain highly qualified professionals in schools, medical clinics, and social and health service agencies. Once-generous policies in support of the poor are now gone and others are on the wane. Social welfare advocates characterize these changes as part of "the race to the bottom."

The irony of it all is striking. Even though many special educators and other child advocates promote inclusion of special needs children in general classrooms, social exclusion is occurring in America's cities and rural communities. Meanwhile, almost one third of Americans now live in walled-in communities characterized by concentrated advantage (e.g. Putnam, 2000). Each of these two extremesconcentrated advantage and concentrated disadvantage-has been called "a fortress community." Each has its "enclave institutions." Private schools always have been enclave institutions, and, thanks to new voucher plans, publicly supported enclave institutions are developing. At the same time, many of the nation's full-service schools are enclave institutions in fortress communities plagued by concentrated disadvantage. ${ }^{y}$

In brief, as poverty is normalized and neglected, and as profound social and economic isolation is becoming commonplace, American democracy is threatened. Schools depend on democracy. Along with families and community

\footnotetext{
"Consider, for example, the popular Children's Aid Society Full-service Schools in Washington Heights, New York. Visitors can take a yellow cab to visit. but since the cab drivers and their companies do not feel safe there. it is more difficult to leave. Washington Heights is thus a fortress community, and its full-service schools, as wonderful as they are, qualify as enclave institutions.
}

associations, schools are the chief institutions for promoting and sustaining a strong democracy.

Ultimately, all of this new-century work is about promoting and ensuring the well-being of every American citizen, especially the children. Service integration and interprofessional collaboration have to support collective citizen engagement, promoting collaboration among citizens and supporting norms of reciprocity. Reciprocity means helping others and being helped, all the while upholding constitutional rights and encouraging others to honor their responsibilities. Americans allegedly once knew how to do this newcentury work. So some of it involves going "back to the future" (Lawson, 2001). Nevertheless, other facets will have to be invented because the global age presents unprecedented challenges and opportunities.

Thus, when we claim that this important combination of new- and old-century work is part of an emergent, fifth wave of service integration (which we could not address here), we also are inviting readers' engagement in something better than today's well intended, important, but insufficient approaches. We conclude, therefore, by claiming that the work of integrating services, collaborating, and developing connections with schools is ultimately about promoting individual, family, and collective well-being, safeguarding, and strengthening democracy for us, our children, and our children's children.

\section{REFERENCES}

Abbott. A. (1988). The system of professions: An essay on the division of expert labor. Chicago: University of Chicago Press.

Ackerson. B., \& Harrison, D. (2000). Practitioners' perceptions of empowerment. Families in Society: Joumal of Contemporary Human Services, $81,238-246$.

Adams, P. \& Nelson, K. (1995). (Eds.). Reinventing human services: Community - and family-centered practice. New York: Aldine de Gruyter.

Adelman, H., \& Taylor, L. (1997a). Addressing barriers to learning: Beyond school-linked services and full-service schools. American Joumal of Orhopsychiatry; $6,108-421$.

Adelman, H., \& Taylor, L. (1997b). Toward a scale-up model for replicating new approaches to schooling. Journal of Educational \& Psychological Consultation, 5, 197-230.

Adelman, H., \& Taylor, L. (1998). Reframing mental health in schools and expanding school reform. Educational Psychologist. 33(4), 135-152.

Adelman, H. \& Taylor, L. (2000). Looking at school health and school reform policy through the lens of addressing barriers to learning. Children's Services: Social Policy, Research, and Practice, 3, 117-132.

Alameda-Lawson. T., \& Lawson, M. (2000, February). Consumer-led community collaboratives: Building social cultural capital and promoting cultural democracy: Paper presented to Council on Social Work Education, New York.

American Academy of Pediatrics. (1994). Principles to link by integrating education, health and human services for children, youth and families: Systems that are community-based and school-linked. Washington. DC: Author.

Annie E. Casey Foundation. (1995). The path of most resistance. Baltimore: Author.

Argyris, C. (1999). On organizational leaming. London: Blackwell Business. 
Armstrong, K. (1997). Launching a family-centered, neighborhood-based human services system: Lessons from working the hallways and streetcorners. Administration in Social Work, 2I(3/4), 109-126.

Benson, L., \& Harkavy, I. (1997). School and community in the global society: A Neo-Deweyian theory of community problem-solving schools and cosmopolitan neighborly communities and a NeoDeweyian "manifesto" to dynamically connect school and community. Universities and Community Schools, 5(1-2), 11-69.

Bickman, L. (1996). A continuum of care: More is not always better. American Psychologist, 51, 689-701.

Briar-Lawson. K., \& Drews, J. (1998). School-based service integration: Lessons learned and future challenges. In D. van Veen, C. Day, \& G. Walraven (Eds.), Multi-service schools: Integrated senices for children and youth at risk (pp. 49-64). Leuven/Appeldorn. The Netherlands; Garant Publishers.

Briar-Lawson, K., \& Lawson. H. (1998), Collaboration and integrated, community-based strategies on behalf of individuals and families in rural areas. In S. Jones \& J. Zlotnik (Eds.), Preparing helping professionals to meet community needs: Generalizing from the rural experience (pp. 111-126). Alexandria, VA: Council on Social Work Education.

Briar-Lawson, K., Lawson, H., Petersen, N., Harris, N., Sallee, A., Hoffman. T., \& Derezotes, D. (1999. January). Meeting the co-occurring needs of child welfare families through collaboration. Paper presented at Society for Social Work and Research, Austin, TX.

Bruner, C., \& Parachini, L. (1997). Building community: Exploring new relationships across senice systems reform, community organizing. and community economic development. Washington, DC: Institute for Educational Leadership \& Together We Can.

Calfee, C., Wittmer, F., \& Meredith, M. (1998). Building a full-service school: A step-by-step guide. San Francisco: Jossey-Bass.

Caplan. G., \& Caplan. R. (2000). Principles of community psychiatry. Community Mental Health Journal, 36(1) 7- 24.

Cappella, E., \& Larner, M. (1999). America’s schoolchildren: Past, present, and future. The Future of Children, 9(2), 21-29.

Christiansen. H. Goulet, L, Krentz, C., \& Maeers, M. (1997). Recreating relationships: Collaboration and educational reform. Albany, NY: SUNY Press.

Cocozza. J., \& Skowyra. K. (2000). Youth with mental health disorders: Issues and emerging responses. Juvenile Justice, 7(1), 3-13.

Comer, J. Haynes, N., Joyner, E., \& Ben-Avie, M. (1996). Rallying the whole village: The Comer process for reforming education. New York: Teachers College Press.

Corrigan, D., \& Udas, K. (1996). Creating collaborative, child- and familycentered education, health and human service systems. In J. Sikula, T. Buttery, \& E. Guyton (Eds), Handbook of research on teacher education (pp. 893-921). New York: MacMillan.

Crowson, R.. Boyd, W., \& Mawhinney, H. (1996). (Eds.). The politics of education and the new institutionalism: Reinventing the American school. London: Falmer Press.

Cowger, C. (1998). Clientilism and clientification: Impediments to strengthsbased social work practice. Sociology \& Social Welfare, 25(1), 25-38.

Dryfoos, J. (1994). Full-service schools: A revolution in health and social senices for children, youth and families. San Francisco: Jossey-Bass.

Dryfoos, J. (1998). Safe passage: Making it through adolescence in a risky society: New York: Oxford University Press.

Feikema, R., Segalavich, J., \& Jeffries, S. (1997). From child development to community development: One agency's journey. Families in societ:: Sournal of Contemporary Human Services, 78, 185-195.

Foster-Fishman, P. Salem. D., Allen, N, \& Fahrbach, K. (1999). Ecological factors impacting provider attitudes toward human service delivery reform. American Joumal of Community Psychology, 27, 785-816.

Franklin, C.. \& Streeter, H. (1996). School reform: Linking public schools with human services. Social Work, 40, 773-782.

Gardner. S. (1994). Conclusion. In L. Adler \& S. Gardner (Eds.). The politics of linking schools and social services (pp. 189-200). Washington. DC \& London: Falmer Press.

Gardner. S. (1999). Beyond collaboration to results: Hard choices in the future of services to children and families. Fullerton, CA: Center for Collaboration for Children, California State University.
Gerry, M. (in press). Service integration and achieving the goals of school reform. In W. Sailor (Ed.), Inclusive education and school/community partnerships. New York: Teachers College Press.

Goodlad, J. (1984). A place called school. New York: McGraw Hill.

Halpern, R. (1999a). After-school programs for low income children: Promises and challenges. The Future of Children, 9(2), 81-95.

Halpern, R. (1999b). Fragile families, fragile solutions: A history of supportive services for families in poverty. New York: Columbia University Press.

Hassett, S., \& Austin, M. (1997). Service integration: Something old and something new. Administration in Social Work, 21(3/4), 9-29.

Hatch, T. (1998). How community action contributes to achievement. Educational Leadership, 55(8), 16-19.

Haveman, R., \& Wolfe, B. (1995). Succeeding generations: On the effects of investments in children. New York: Russell Sage Foundation.

Himmelman, A. (1996). Communities working collaboratively for a change. Minneapolis: Himmelman Consulting.

Honig, M., Kahne, J., \& McLaughlin, M. (in press). School-community connections: Strengthening opportunity to learn and opportunity to teach. In V. Richardson (Ed.), Fourth handbook of research on teaching. New York: Macmillan.

Hooper-Briar, K., \& Lawson, H. (1994). Serving children, youth and families through interprofessional collaboration and service integration: $A$ framework for action.

Kagan, S., Goffin, S., Golub, S., \& Pritchard, E. (1995). Toward systemic reform: Service integration for young children and their families. Des Moines, IA: National Center for Service Integration.

Kamradt, B. (2000). Wraparound Milwaukee. Juvenile Justice, 7(1), 14-23.

Keith, N. (1996). Can urban school reform and community development be joined? The potential of community schools. Education \& Urban Society, $28,237-268$

Lawson, H. (1998). Collaborative educational leadership for 21 st century school communities. In D. van Veen, C. Day, \& G. Walraven (Eds.), Multi-service schools: Integrated services for children and youth at risk (pp. 173-193). Leuven/Appeldorn, The Netherlands: Garant Publishers.

Lawson, H. (1999a). Journey analysis: A framework for integrating consultation and evaluation in complex change initiatives. Journal of Educational \& Psychological Consultation, 10, 145-172.

Lawson, H. (1999b). Two frameworks for analyzing relationships among school communities, teacher education, and interprofessional education and training programs. Teacher Education Quarterly, 28(5), 9-30.

Lawson, H. (1999c). Two new mental models for schools and their implications for principals' roles, responsibilities, and preparation. National Association of Secondary School Principals' Bulletin (in publication).

Lawson, H. (2001). Back to the future: New century professionalism and collaborative leadership for comprehensive, community-based systems of care. In A. Sallee, H. Lawson, \& K. Briar-Lawson (Eds.), Innovative practices with vulnerable children and families. (pp. 393-419). Dubuque, IA: Eddie Bowers Publishers.

Lawson, H. (in press a). From community involvement and service learning to engaged universities. Universities and Community Schools.

Lawson, H. (in press b). Introducing globalization's challenges and opportunities and analyzing economic globalization and liberalization. In K. Briar-Lawson, H. Lawson, C. Hennon, \& A. Jones, Family-centered policies and practices: International implications. New York: Columbia University Press.

Lawson, H. \& Associates. (1999). Developing caring school communities for children and youth: Unity of purpose for strong families, schools, community agencies and neighborhood organizations. An interprofessional leadership guide for facilitators, prepared for the Missouri Department of Elementary and Secondary Education, Jefferson City, MO.

Lawson, H., \& Briar-Lawson, K. (1997). Connecting the dots: Integrating school reform, school-linked services, parent involvement and community schools. Oxford, OH: Danforth Foundation \& Institute for Educational Renewal at Miami University.

Lawson, H., \& Barkdull, C. (2001). Gaining the collaborative advantage and promoting systems and cross-systems change. In A. Sallee, H. Lawson, \& K. Briar-Lawson (Eds.), Innovative practices with vulnerable children and families. (pp. 245-270). Dubuque, IA: Eddie Bow- 
ers Publishers.

Mattessich, P., \& Monsey. B. (1992). Collaboration: What makes it work (5th ed.). St. Paul, MN: Amherst H. Wilder Foundation.

McKnight, J. (1995). The careless society: Community and its counterfeits. New York: Basic Books.

McKnight, J. (1997). A 21 st century map for healthy communities and families. Families in Society: The Journal of Contemporary Human Services, $78,117-127$.

Melaville, A., \& Blank, M. (1998). Learning together: The developing field of school-community initiatives. Flint, MI: Mont Foundation, Institute for Educational Leadership and National Center for Community Education.

Mitchell, D., \& Scott, L. (1994). Professional and institutional perspectives on interagency collaboration. In L. Adler \& S. Gardner (Eds.), The politlcs of linking schools and social services (pp. 75-92). Washington, DC \& London: Falmer Press.

Mooney, J., Kline, P, \& Davoren, J. (1999). Collaborative interventions: Promoting psychosocial competence and academic achievement. In R. Tourse \& J. Mooney (Eds.), Collaborative practice: School and human service partnerships (pp. 105-136). Westport, CT \& London: Praeger.

Office of Economic Cooperation and Development. (1998). Case studies in integrated services for children and youth at risk: A world view. Paris: Author.

O'Looney, J. (1996). Redesigning the work of human services. Westport. CT: Quorum Books.

Putnam, R. (2000). Bowling alone: The collapse and revival of American community. New York: Simon \& Schuster.

Quinn. K., \& Cumblad. C. (1994). Service providers' perceptions of interagency collaboration in their communities. Joumal of Emotional \& Behavioral Disorders, 2, 109-116.

People Helping People (1997, Summer). Walking our talk in the neighborhoods: Building professional/natural helper partnerships, 28, 54-63.

Sailor, W. (1991). Special education in the restructured school. Remedial \& Special Education, 12(6), 8-22.

Sailor, W. (1996). New structures and systems change for comprehensive positive behavioral support. In L. K. Koegel, R. L. Koegel, \& G. Dunlap (Eds.), Positive behavioral support: Including people with difficult behavior in the community (pp. 163-206). Baltimore: Paul $\mathrm{H}$. Brookes.

Sailor, W. (in press). Devolution, school/ community/ family partnerships. and inclusive education. In W. Sailor (Ed.), Inclusive education and school/community partnerships. New York: Teachers College Press.

Sailor, W., Kleinhammer-Tramill, J., Skrtic, T., \& Oas, B. K. (1996). Family participation in New Community Schools. In G. H. S. Singer, L. E. Powers, \& A. L. Olson, Redefining family support: Innovations in public-private partnerships (pp. 313-332). Baltimore: Paul H. Brookes.

Sailor, W., \& Skrtic, T. (1996). School/community partnerships and educational reform: Introduction to the topical issue. Remedial \& Special Education, 17, 267-270.

Sandfort, J. (1999). The structural impediments of human service collaboration: Examining welfare reform at the front lines. Social Service Review, 73, 314-339.

Sarason, S., \& Lorentz, E. (1998). Crossing boundaries: Collaboration, coordination and the redefinition of resources. San Francisco: JosseyBass.

Schön, D. (1983). The reflective practitioner: How professionals think in action. New York: Basic Books.

Schorr, L. (1997). Common purpose: Strengthening families and neighbor- hoods to rebuild America. New York: Anchor Books Doubleday.

Sen, A. (1999). Development as freedom. New York: Alfred A. Knopf.

Skrtic, T. (2000) Civic professionalism and the struggle over needs. Keynote address: Office of Special Education Programs (OSEP) Leadership Training Conference. July 11-12. Washington, DC.

Skrtic, T., \& Sailor, W. (1996). School-linked services integration: Crisis and opportunity in the transition to postmodern society. Remedial \& Special Education, 17, 271-283.

Slavin, R., Madden, N., Dolan, L., \& Wasik, B. (1996). Every child, every school: Success for all. Thousand Oaks, CA: Corwin Press.

Tyack, D. (1992). Health and social services in schools: Historical perspectives. The Future of Children, 2(1), 19-31.

Tyack, D., \& Cuban, L. (1995). Tinkering toward utopia: A century of public school reform. Cambridge, MA: Harvard University Press.

Tye, B. (2000). Hard truths: Uncovering the deep structure of schooling. New York: Teachers College Press.

van Veen, D., Day, C., \& Walraven, G. (1998). (Eds), Multi-service schools: Integrated services for children at risk. Leuven/Appeldoorn, The Netherlands: Garant.

Van Wagoner, P., Boyer, R., Wisen, M., Ashton, D., \& Lawson, H. (2001). Introducing child welfare neighborhood teams that promote collaboration and community-based systems of care. In A. Sallee, H. Lawson, \& K. Briar-Lawson (Eds.), Innovative practices with vulnerable children and families. (pp. 323-360). Dubuque, IA: Eddie Bowers Publishers, Inc.

Wagner, M, Newman, L., \& Golan, S., (1996). California's healthy start school-linked services initiative: Results for children and families. Menlo Park, CA: SRI International.

Waldfogel, J. (1997). The new wave of service integration. Social Service Review, 71, 463-484.

Warren, C. (1999, January). Lessons from the evaluation of New Jersey's school-based youth services program. Paper presented at National Conference on Improving Results for Children and Families by Connecting Collaborative Services with School Reform Efforts, Laboratory for Student Success at the Temple University Center for Research in Human Development and Education and the Council of Chief State School Officers, Washington, DC.

Wenger, E. (1999). Communities of practice: Learning, meaning, and identity. Oxford, UK: Cambridge University Press.

White, J., \& Wehlage, G. (1995). Community collaboration: If it is such a good idea, why is it so hard? Educational Evaluation and Policy Analysis, 17(1), 23-38.

Winer, M., \& Ray, K. (2000). Collaboration handbook: Creating, sustaining, and enjoying the journey. Minneapolis: Amberst H. Wilder Foundation.

Wynn, J., Meyer, S., \& Richards-Schuster, K. (1999, January). Furthering education: The relationship of schools and other organizations. Paper presented at the National Conference on Improving Results for Children and Families by Connecting Collaborative Services with School Reform Efforts, Laboratory for Student Success at The Temple University Center for Research in Human Development and Education and the Council of Chief State School Officers, Washington, DC.

Zigler, E. (1997). Supporting children and families in the schools: The school of the 21 st century. American Joumal of Orthopsychiatry, 67, $396-407$. 